\title{
Comparison of Four Common Gold Nanoparticles for Photothermal Cancer Therapy: A Review
}

\author{
Sabrina N. Saiphoo, Cassidy M. Rose, Alexander T. Dunn, Dwji J. Padia and Muhammad H. \\ Hasan
}

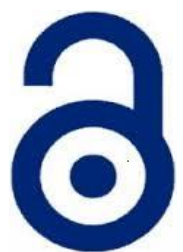

Received: 28 May 2020

Accepted: 23 August 2020

Published: 20 October 2020

Publisher: Deer Hill Publications

(c) 2020 The Author(s)

Creative Commons: CC BY 4.0

\begin{abstract}
Current cancer treatment options, including surgery, chemotherapy and radiation therapy, often cause damage to healthy tissue and reduce a patient's quality of life with well-known side effects, such as pain, infection and nerve damage. Recent research has shown that gold nanoparticles used as photothermal agents in photothermal therapy may pose as an alternative to traditional treatments. This great potential is due to their ability to selectively accumulate in cancerous tissue, efficiently absorb near-infrared light, and kill cancerous tissue without harming surrounding cells. Gold nanoparticles show promise in increasing treatment efficacy and reducing the side effects associated with cancer therapy. While recent studies show the potential of gold nanoparticles, the existing literature is limited in drawing comparisons between studies and practical use for photothermal therapy. This paper reviews notable studies on four common gold nanoparticles used in the therapeutic treatment of cancer: gold nanocages, gold nanospheres, gold nanorods, and gold nanoshells. By comparing key characteristics of the particles', including their synthesis, toxicity, absorption spectrum, and selective photothermal lethality, gold nanospheres can be recommended for use in photothermal therapy. Although forms of each gold nanoparticle were found to have a low toxicity, gold nanospheres can be rapidly synthesized and appear to exceed in selective photothermal lethality and immature tumour accumulation. Due to these advantages in using gold nanospheres for photothermal therapy, cancer could be treated more effectively and improve patient prognosis.
\end{abstract}

Keywords: Gold nanoparticles, cancer therapy, photothermal agents, photothermal therapy, near infrared radiation, nanorods, nanoshells, nanocages, nanospheres, hyperthermia

\section{INTRODUCTION}

Cancer is the leading cause of death in Canada with 1 in 4 cases being fatal [1]. In 2020, 225,800 people in Canada are expected to be diagnosed with cancer [2]. Cancer also places a large burden on the patient and a financial strain on the country [3]. In 2008, the estimated total cost of cancer in Canada was \$4.4 billion [3]. Cancer's mortality rate is decreasing due to advancements in the medical field, but remains high globally [4]. This is largely caused by the damage cancer causes to healthy tissue and the large strain placed on the body during conventional treatment [5].

Current cancer treatments include surgery, chemotherapy, radiotherapy, gene therapy, hormonal therapy, immunotherapy, and hyperthermia [6,7]. These treatments can have a wide range of side effects, including pain, fatigue, and nausea [8]. Traditional treatments like chemotherapy and radiation therapy cause damage to noncancerous, rapidly-dividing cells [6]. Radiation therapy also causes cell death or halts cell division by inducing DNA damage using ionizing radiation [9]. A major disadvantage of these treatment methods lies in the fact that they are non-specific, causing healthy, normal cells to be damaged [6].

Recently, extensive research has been conducted concerning the application of nanoparticles (NPs) as they have shown promise in both drug-targeting and hyperthermia treatments [10,11, 12]. According to the International Union of Pure and Applied Chemistry (IUPAC), NPs are microscopic particles that have dimensions ranging between 1 and $100 \mathrm{~nm}[13,14]$. The use of NPs in cancer treatments has shown the potential to increase the localization and targeting

Sabrina N. Saiphoo', Cassidy M. Rose', Alexander T. Dunn', Dwji J. Padia' and Muhammad H. Hasan² ${ }^{2}$ 'Department of Electrical, Computer, and Biomedical Engineering

2Departmenty of Mechanical and Industrial Engineering

Ryerson University, Canada

Email: hasibulhasan@ryerson.ca

Reference: Saiphoo, S. N., Rose, C. M., Dunn, A. T., Padia, D. J., Hasan, M. H. (2020). Comparison of Four Common Gold Nanoparticles for Photothermal Cancer Therapy: A Review. International Journal of Engineering Materials and Manufacture, 5(4), 116-129. 
abilities of current treatments [15]. This can be accomplished by using NPs as a photothermal agent (PTA) in targeted hyperthermia $[16,10]$.

Hyperthermia is a non-invasive cancer therapy where malignant cells are exposed to localized heat greater than $43^{\circ} \mathrm{C}[17,18,19]$. Conventional hyperthermia can cause damage to surrounding tissues, burns, pain at the target site, blood clots, infection, and swelling [20,21]. For this reason, a promising method to achieve hyperthermia is using PTAs that accumulate selectively in tumour tissue and cause heating in a localized area when exposed to electromagnetic radiation of a certain frequency $[16,22]$. This process is known as photothermal therapy (PTT) [17, 41].

The selective accumulation of NPs in tumours is possible due to their poorly formed vasculature, which is more permeable than that of normal tissue [10]. Metallic NPs can strongly absorb and scatter specific wavelengths of light and the resulting resonant energy is converted to heat [23]. PTT typically uses near-infrared (NIR) radiation since it offers a low attenuation in tissue, allowing for energy penetration into deep tissues $[10,24]$. Using NIR radiation also causes minimal thermal damage to healthy tissue $[10,12]$.

Due to the high absorption of gold nanoparticles (AuNPs) in the NIR range and their ability to rapidly heat under irradiation, their potential use in PTT is an active area of research $[21,25,26]$. The absorption peaks of these AuNPs in specific regions of the electromagnetic spectrum are due to the localized surface plasmon resonance (LSPR) [22, 25]. Since AuNPs are conductive and smaller than visible light wavelengths, the electric field from electromagnetic radiation can excite electrons of a conduction band [22]. The result is localized plasmon oscillations, whose resonant frequency depends on the geometry and size of the AuNP [22]. This resonance generates the heat observed during PTT [22].

AuNPs have properties unique from other materials being studied for use in cancer treatment applications, such as iron-, polymer-, and lipid-based NPs [13]. They have been shown to have adjustable properties, including the ability to optimize the relative proportions of light scattering and absorption based on the application [10]. AuNPs are also unique in being able to retain their optical properties within the body for a long time [21]. AuNPs are injected into the body and passively accumulate in tumours before the NIR laser is used to excite the particles and generate internal heating [23]. The biological effects of this localized increase in temperature include the nucleation and growth of bubbles on tumour tissues and denaturation in cells [11]. When these growing bubbles rupture, they can then apply mechanical stress to the target cells and cause damage [11].

When comparing different PTAs for use in PTT, it is important to consider a few key characteristics and properties. Firstly, the toxicity of NPs should be low because, otherwise, they may kill healthy cells and cause permanent damage [27]. The particle must also selectively accumulate in the target tissue and efficiently heat under electromagnetic radiation $[15,10]$. Another key factor is the size of NPs since this may affect tissue accumulation and uptake by cancerous cells [10]. Tumour vasculature can have varying sizes of fenestrations based on age and, therefore, a smaller particle size might be required for accumulation in early-stage tumour tissue [10]. The absorption spectrum of the particles is also important in determining the functionality of a PTA [10]. The absorption peak should lie in the NIR region to ensure sufficient tissue penetration and energy absorption can occur during PTT [10, 28].

This paper will compare common AuNPs for use in PTT with a NIR laser. The NPs being compared will be gold nanocages (AuNCs), gold nanorods (AuNRs), gold nanospheres (AuNSs), and gold nanoshells (AuNShs). By reviewing notable studies on the aforementioned parameters, an ideal AuNP will be selected for use in PTT with the goal of informing and focusing the scope of future research efforts.

\section{GOLD NANOCAGES}

AuNCs are a specific morphology of AuNP that are widely studied for use in PTT $[29,30]$. In 1989, studies performed on AuNPs to test their effectiveness for PTT found that AuNCs had promising multi-functionalization and encapsulation abilities [31]. This means their surfaces could be easily modified to achieve enhanced tumour-specific tissue accumulation [31]. AuNCs act as photothermal transducers, their large surface area converts light into heat [29, 32]. AuNCs are used because of their high photothermal efficiency, low toxicity, high tissue accumulation, and high cell killing efficiency $[29,33]$. This section will review several studies to evaluate the PTT efficacy of AuNCs.

\subsection{Synthesis}

Chen and colleagues [29] described how uncoated AuNCs are synthesized by a simple galvanic replacement reaction between silver nanocubes and $\mathrm{HAuCl}_{4}$ [29]. Galvanic replacement reactions are redox reactions between solid metal $\mathrm{Ag}$ nanocubes and $\mathrm{Au}$ ions from $\mathrm{HAuCl}_{4}$ [29]. This process synthesizes the uncoated AuNC structure, giving it certain intrinsic properties, such as the LSPR peak of roughly $800 \mathrm{~nm}$, edge length of $47 \mathrm{~nm}$, and diameter of $99 \mathrm{~nm}$ found in this study [29]. The characteristics of AuNCs can be further modified by changing the surface coating [29]. The surface coating also allows for specific tumour cell targeting and can change the efficiency of the photothermal treatment [29]. The nanocage surface can then be covered with a coating of heterofunctional polyethylene glycol (PEG) with a sulfhydryl group at one end and a methoxy group at the other [29]. This gave rise to new dimensions, where the edge length was $48 \mathrm{~nm}$ and the diameter was $92.2 \mathrm{~nm}$ [29].

Jenkins and colleagues [33] described a similar method for synthesizing AuNCs, however, they used a different surface coating for their experiments [33]. The AuNCs were coated with polydopamine (PDA), creating polydopamine-coated AuNCs (AuNC@PDA) and then further conjugated with Anginex to synthesize AuNC@PDA- 
Ax [33]. This coating of the AuNCs altered their dimensions and absorption properties [33]. The edge length produced in this experiment was $45.6 \mathrm{~nm}$ and the hydrodynamic diameter was $132 \mathrm{~nm}$ [33]. The LSPR peak was also slightly lower than that in the study by Chen et al. [29] at $794 \mathrm{~nm}$ [33].

\subsection{Toxicity}

According to Jenkins et al. [33] the toxicity of a AuNP has more to do with its coating and size, rather than shape [33]. Jenkins et al. [33] studied the bodies of test mice post-irradiation to assess the biodistribution and tissue concentration of the AuNC@PDA and AuNC@PDA-Ax [33]. They found relatively high concentrations of AuNC in the liver and spleen and low concentrations in the kidneys [33]. This was expected due to the size of the AuNCs being much larger than the renal filtration limit, preventing them from entering the kidneys [33]. A high distribution of AuNC@PDA-Ax was found in the lungs of the mice, but AuNC@PDA was found in a much lower percentage [33]. This is interesting because it indicates the specific coatings of AuNCs can change the distribution of AuNCs, affecting the degree of toxicity in specific organs [33]. Jenkins et al. [33] concluded that bare, uncoated AuNCs are completely non-toxic and the PDA-Ax surface coating is entirely responsible for any toxicity exhibited [33].

\subsection{Selective Photothermal-Induced Cell Death}

A key factor in the effectiveness of AuNCs in PTT is their ability to passively accumulate at the tumour site, while minimally affecting healthy cells [29]. In a study by Chen and colleagues [29], this was tested by harvesting the tumours and organs of the mice injected with AuNCs $96 \mathrm{hr}$ after PTT and using inductively-coupled plasma mass spectrometry (ICP-MS) to analyse the accumulation of AuNCs [29].

Chen and coworkers [29] found that the NCswere essentially completely cleared from the blood and muscle tissue with respective concentrations of $0.04 \pm 0.03 \% \mathrm{ID} / \mathrm{g}$ and $0.80 \pm 0.12 \% \mathrm{ID} / \mathrm{g}$ (percent initial dose per gram of tissue) after $96 \mathrm{hr}$ [29]. The passive accumulation at the tumour site was efficient with a particle concentration of $5.7 \% \mathrm{ID} / \mathrm{g}$ [29]. Upon qualitative observation, the entire surface of the tumour was almost fully covered with AuNCs [29]. The three-dimensional spatial distribution of the NCswas examined by cutting the tumour into small pieces and each piece was weighed and analysed using ICP-MS [29]. As seen in Figure 1, the edges had the highest concentration of NCs, while the centre had the lowest concentration, with a linear change in concentration between these areas [29]. This is due to the intravenous nature of the nanocage injection, as most tumour blood vessels are on its surface [29]. The NCs were observed to penetrate the leaky blood vessels of the tumour over time, allowing for uniform heat generation during PTT [26, 29]. The results of Jenkins and colleagues [33] experiment agree with those of Chen and coworkers [29], as the AuNC@PDA had a tumour accumulation of 22 particles/g and AuNC@PDA-Ax had an even better accumulation of 65 particles/g [33].
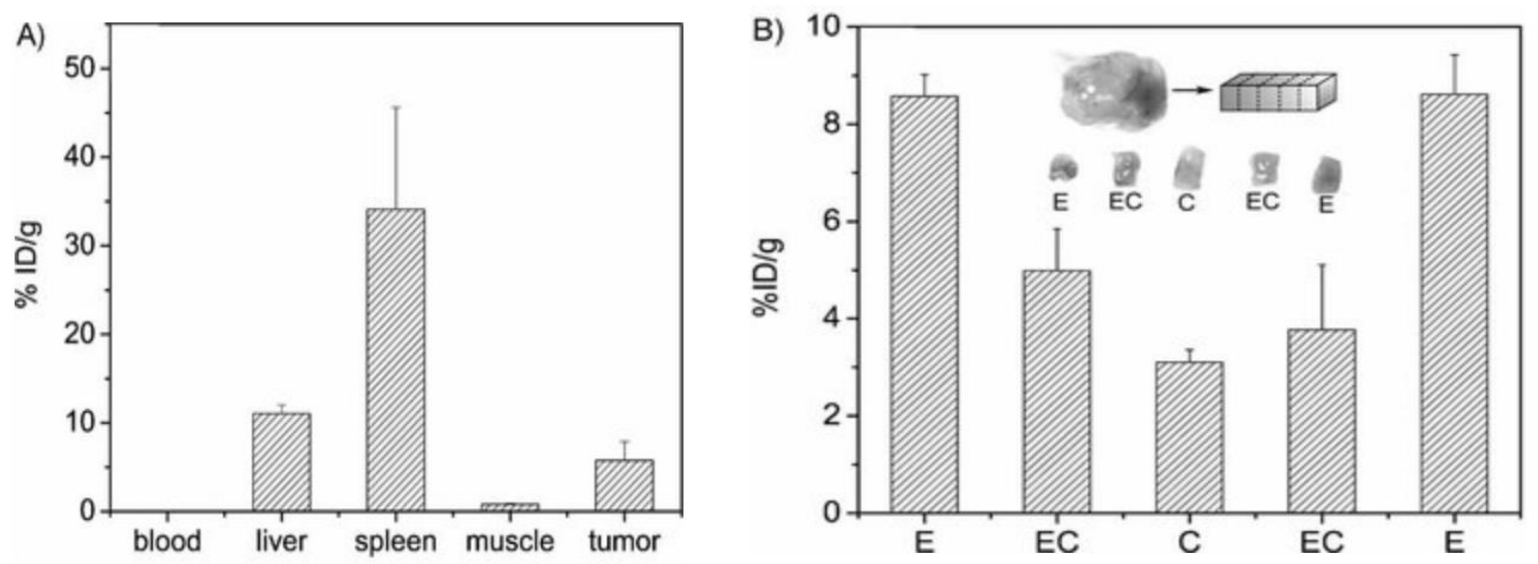

Figure 1: (A) Biodistribution of the AuNC in various organs (B) Distribution of the AuNC within the tumour layers, where $E$ is edge and $C$ is center [29].

Chen and colleagues [29] tested the selective destruction of tumourous tissue using AuNCs by injecting 10 mice with cancer cells (U87wtEGFR) subcutaneously in their right and left ear flanks [29]. The mice were then divided into two even groups of five once the implanted tumours had grown to a volume of $200-400 \mathrm{~mm}^{3}$ [29]. The first group received $100 \mu \mathrm{L}$ of $9 \times 10^{12}$ particle/mL PEGylated AuNCs in a phosphate-buffered saline (PBS) solution, while the second group only received an equal volume of saline, both through intravenous injections [29]. The mice were left for $72 \mathrm{hr}$ before beginning PTT [29]. Both group's right ear flanks were subjected to a steady beam $808 \mathrm{~nm}$ diode laser at a power density of $0.7 \mathrm{~W} / \mathrm{cm}^{2}$ for $10 \mathrm{~min}$ [29].

Chen and coworkers [29] noted the group with the AuNC injections had a maximum temperature reading of 54 ${ }^{\circ} \mathrm{C}$, while the saline-injected group's temperature never passed the $37^{\circ} \mathrm{C}$ mark [29]. $24 \mathrm{hr}$ post-irradiation, it was observed that in the group that underwent the AuNCs treatment, the metabolism of $70 \%$ of the tumour cells was 
halted, effectively rendering them deceased with minimal damage to healthy cells [29]. Upon histological examination by electron microscopy, there was evidence of coagulative necrosis (cell death), an abundance of destroyed chromatin fragments throughout the cytoplasm (karyorrhectic debris), and considerable regions of karyolysis (destruction of the nucleus) [29].

\section{GOLD NANOSPHERES}

AuNSs are solid gold NPs with a spherical shape and are among the smaller of the AuNPs being studied for applications in hyperthermia [10]. Their absorption peak lies near $530 \mathrm{~nm}$ in the visible light region but can be shifted to the NIR region by clustering AuNSs together within or outside of target cells $[10,34]$. They have also been studied separately for applications in diagnostic imaging and used in vivo as a radiotracer [10,35, 36, 37]. As one of the older forms of AuNPs, many studies showed their potential in PTT were performed in the early 2000s [10]. Pitsillides et al. [38] first proposed a method that used AuNPs to achieve selective cell killing using laser pulses to irradiate cells that had been incubated with antibody conjugated 20 and $30 \mathrm{~nm}$ AuNSs [21]. Using this method, energy was selectively delivered to AuNSs, causing microscopic cellular damage, high localized peak temperatures, and cell death [38]. This study has been built upon in more recent work [21, 10], which will be explored in this section to evaluate AuNS's potential efficacy in PTT.

\subsection{Synthesis}

Compared to other AuNPs, AuNSs are relatively simple to synthesize [10]. Typically, AuNSs are produced using a citrate-mediated reduction of chloroauric acid $\left(\mathrm{HAuCl}_{4}\right)[24,25,39]$. In a study by Chen and coworkers [40], $\mathrm{HAuCl}_{4}$ $(1 \mathrm{~mL}, 0.25 \mathrm{mM})$ was added to $\mathrm{H}_{2} \mathrm{O}(90 \mathrm{~mL})$, then stirred at $25^{\circ} \mathrm{C} 1 \mathrm{~min}$. Next sodium citrate $(2 \mathrm{~mL}, 38.8 \mathrm{mM})$ was added to this solution, which was then stirred for an additional minute before adding $\mathrm{NaBH}_{4}(0.6 \mathrm{~mL}, 0.1 \mathrm{M})$. The reaction mixture was stirred at $0-4{ }^{\circ} \mathrm{C}$ for 5-10 min, depending on the desired size. To vary the diameters of the AuNSs between 3 to $100 \mathrm{~nm}$, the volume of seed colloid $\left(\mathrm{HAuCl}_{4}\right)$ added was also varied [40]. A simple, energyefficient, and rapid synthesis method using microwave heating has also been used by Liu and coworkers [39]. This method appears promising for the large-scale production of NPsthat would be required for the widespread application of AuNSs in healthcare [39].

\subsection{Toxicity}

The safety of using AuNSs in the human body is well-known through decades of their use as a radiotracer and gold can remain within cells without reacting for long periods of time $[35,36,37,38]$. However, Chen and coworkers further evaluated the toxicity of AuNSs over time in mice and found a correlation between NP size and toxicity [40]. In this study, $8 \mathrm{mg}$ per week of uncoated AuNSs with 3, 5, 8, 12, 17, 37, 50, and $100 \mathrm{~nm}$ diameters were injected intraperitoneally into mice [40]. These AuNSs were prepared according to the procedure in section 4.2 [40]. Prior to injection, the AuNSs were purified by dialysis using PBS at a pH of 7.4 [40]. At the end of the experiment, the mice's liver, lungs, spleen, and brain were isolated for analysis by ex vivo Coherent anti-Stoke Raman scattering microscopy and weighed [40].

Their results indicated that both AuNPs with larger and smaller diameters were non-toxic with notable toxicity observed for intermediate diameters [40]. Neither toxic nor harmful effects were observed for those injected with AuNSs of diameters of 3,5,50, and $100 \mathrm{~nm}$ [40]. Toxic effects like changes in fur colour, weight loss, and fatigue were observed in the mice injected with AuNSs ranging between 8 to $37 \mathrm{~nm}$ in diameter [40]. They also developed hemorrhaging, rashes, and bruising on their skin, as well as irregular spinal shapes [40]. The heart, brain, and kidney from the diseased groups were found to be distinctly different from the normal, healthy tissues of the control mice [40]. Within the lungs of these mice, emphysema-like damage and a loss of structural integrity were observed [40]. Abnormal amounts of white pulp were discovered in their spleens and a high amount of Kupffer cells were found in their livers [40]. Within 21 days, most of the mice in the 8 to $37 \mathrm{~nm}$ diameter groups died [40].

Therefore, this study showed that the toxicity of AuNSs is size-dependent, with those having diameters less than $5 \mathrm{~nm}$ and between 50 to $100 \mathrm{~nm}$ being non-toxic in vivo in mice [40]. These results indicate that while in previous studies, AuNSs showed low toxicity in cell cultures, they can cause lethal effects in mammals at certain diameters and high enough doses [40]. This is an important factor for further research to ensure the safety of using AuNSs in PTT.

\subsection{Selective Photothermal-Induced Cell Death}

In a study conducted by El-Sayed and colleagues [35], they demonstrated the ability of AuNSs conjugated to antiepithelial growth factor receptor (EGFR) antibodies to selectively damage epithelial carcinoma cells. EGFR is a biomarker that is overexpressed by oral squamous carcinoma cells so antibody conjugation can be used to increase the transportation of nanoparticles specifically to tumour cells $[34,35]$.

In this study, the citrate reduction of $\mathrm{HAuCl}_{4}$ was used to prepare the AuNSs [35]. Using transmission electron microscopy (TEM), the average particle size was found to be $40 \mathrm{~nm}$ [35]. A HEPES buffer (20 mM, pH of 7.4) was added to the AuNSs until an optical density of 0.8 at $530 \mathrm{~nm}$ was achieved [35]. A dilute solution of anti-EGFR monoclonal antibodies was then mixed for 20 min with $10 \mathrm{~mL}$ of the AuNS solution [35]. To prevent aggregation, PEG was added $(0.5 \mathrm{~mL}, 1 \%)$ [35]. Next, the solution was centrifuged and a PBS buffer ( $\mathrm{pH}$ of 7.4) was used to redisperse resulting pellets of anti-EGFR antibodies and AuNSs [35]. 
Table 1: Laser Power Densities per Cell Culture Sample [35]

\begin{tabular}{|c|c|c|}
\hline Cell Type & $\begin{array}{l}\text { Incubated with anti-EGFR antibody } \\
\text { conjugated AuNSs }\end{array}$ & Laser Power Densities (W/ $\left./ \mathrm{cm}^{2}\right)$ \\
\hline Benign $\mathrm{HaCaT}$ & No & $19,25,38,50,64,76$ \\
\hline Benign $\mathrm{HaCaT}$ & Yes & $13,19,25,32,38,45,51,57,64$ \\
\hline $\begin{array}{l}\text { Malignant HOC } 313 \text { clone } 8 \text { and } \\
\text { HSC } 3\end{array}$ & Yes & $13,19,25,32,38,45,51,57,64$ \\
\hline
\end{tabular}

Table 2: Photothermal Cell Destruction Results by Cell Type and Laser [35]

\begin{tabular}{cccc}
\hline Cell Type & $\begin{array}{c}\text { Incubated with anti-EGFR } \\
\text { conjugated AuNSs }\end{array}$ & $\begin{array}{c}\text { Laser Power Density } \\
\left(\text { W/cm }{ }^{2}\right)\end{array}$ & $\begin{array}{c}\text { Approx. Photothermal } \\
\text { Cell Destruction (\%) }\end{array}$ \\
\hline HaCaT & No & $\leq 76$ & 0 \\
HaCaT & Yes & $<57$ & 0 \\
HaCaT & Yes & $\geq 57$ & 100 \\
HSC & Yes & $<19$ & 0 \\
HSC & Yes & $\geq 25$ & 100 \\
$\mathrm{HOC}$ & Yes & $\leq 13$ & 0 \\
$\mathrm{HOC}$ & Yes & $\geq 19$ & 100 \\
\hline
\end{tabular}

Benign human keratinocytes ( $\mathrm{HaCaT}$ ), were used as the control cells and two forms of malignant human oral squamous carcinoma cells (HOC 313 clone 8 and HSC 3) were used as the test sample cells [35]. These cells were submerged in the anti-EGFR antibody conjugated AuNS solution for $40 \mathrm{~min}$ and then rinsed using a PBS buffer [35]. A CW argon laser with a wavelength of $514 \mathrm{~nm}$ was used to irradiate cells for four minutes continuously [35]. The laser power densities that the cells were irradiated at are displayed in Table 1 [35]. To determine cell viability, $0.4 \%$ trypan blue was used to stain cells, which accumulates in dead cells [35]. Optical microscopy was used to examine the cells [35]. The results of this experiment, summarized in Table 2, indicated that cancerous cells treated with antiEGFR conjugated AuNSs could be killed using less than half the amount of laser energy required to kill benign cells [35]. Therefore, this is strong evidence of the ability of AuNSs to selectively kill malignant cells without damage to healthy cells [35].

The use of AuNSs in PTT is disadvantaged by their near $530 \mathrm{~nm}$ wavelength absorbance peak [10]. Ideally, PTT is performed using NIR radiation, which can penetrate and treat deeper tissues than visible light [10, 34, 41, 42]. To overcome this disadvantage, AuNSs can be clustered within or outside of the target cells, shifting their maximum surface plasmon absorption towards the NIR region [10,34, 41, 42]. In a study by Huang et al. [43] that used a similar procedure to the previously detailed experiment by El-Sayed et al. [35], clusters of $30 \mathrm{~nm}$ AuNSs were formed to shift their absorbance peak to the NIR region. Human oral squamous carcinoma cells (HSC3) were incubated with anti-EGFR antibody conjugated AuNSs and untreated cells acted as a control [43]. Cells were irradiated with $100 \mathrm{fs}$ laser pulses with a wavelength of $800 \mathrm{~nm}$ [43]. The results of this study indicated that 20 times less laser power is required to induce photothermal destruction in cells that have been incubated with anti-EGFR antibody conjugated AuNSs than those that were not [43]. This implies that using this method, even higher tumour-cell-specific killing can be achieved using a laser in the NIR region and clusters of AuNSs in PTT [43].

More recently, it was found that photolabile, diazarine-decorated AuNSs can be triggered by a laser to form crosslinked aggregates, shifting their surface plasmon resonance to the NIR region [42]. This novel technique presents an opportunity to precisely treat tumours and minimize damage to healthy cells by selectively triggering only the diazarine-decorated AuNSs within tumour regions. This method could serve as an effective modality for both enhancing photoacoustic imaging and PTT of tumours. An advantage of AuNSs in PTT is the potential to use the formation of microbubbles in a unique theragnostic system that can simultaneously image and treat tumours $[10,44]$. In a study by Lapotko et al. [44], clusters of AuNSs were formed outside target cells, causing observable laser-induced microbubbles and selective damage to target cells. In this experiment, stem cells, myeloid K562 cells, and human patient-derived acute B lymphoblastic leukemia cells were irradiated [44]. Clusters of $30 \mathrm{~nm}$ AuNSs were formed on 
the surface of $\mathrm{K} 562$ and leukemia cells by treating them with monoclonal antibodies [44]. Cells were irradiated individually with $10 \mathrm{~ns}, 532 \mathrm{~nm}$ wavelength laser pulses at 5, 35, and $90 \mathrm{~J} / \mathrm{cm}^{2}$ optical fluences [44]. Cells were also irradiated in a PBS solution with $1 \%$ fetal bovine serum at laser fluences of $0.5-2 \mathrm{~J} / \mathrm{cm}^{2}$ [44]. Photothermal microscopy was used to detect microbubble formation and for live monitoring of cell damage on the nanosecond scale [44]. Trypan blue was used to determine cell death [44].

The results of this experiment indicate the ability of the incubated AuNSs to cause photothermal microbubble formation and selective damage to malignant cells [44]. Bubbles were only observed during the irradiation of target cells that were incubated with antibody conjugated AuNSs [44]. Physical damage was also frequently observed for these cells [44]. At a fluence of $5 \mathrm{~J} / \mathrm{cm}^{2}$, the damage probability was $100 \%$ for targeted cells and $7 \%$ for non-target cells [44]. At a fluence of $35 \mathrm{~J} / \mathrm{cm}^{2}$, the damage probability was also low (9\%) for non-target cells [44]. For the suspended cells, $100 \%$ of tumour cells were damaged compared to $16 \%$ of stem cells at a $1.7 \mathrm{~J} / \mathrm{cm}^{2}$ laser fluence [44].

\section{GOLD NANORODS}

AuNRs are a specific type of AuNP that are elongated in one direction [45]. AuNRs have unique optical and electronic properties that are dependent on the particles' size and aspect ratio [46]. These particles are also anisotropic, which has sparked interest in the biomedical field for applications in drug and gene delivery, as contrast agents in optical imaging, and as PTAs in cancer therapy [45, 47, 48]. This interest is due to the presence of two electromagnetic absorption peaks with a bandgap that is extremely tunable [45]. These absorption peaks correspond to the transverse and longitudinal edges and are caused by localized surface plasmon resonance in the NP [45, 49]. The LSPR can range from 600 to $1300 \mathrm{~nm}[45,46,50]$. This section of the paper will look at notable studies on the use of AuNR in hyperthermia to analyse its use in cancer treatment.

\subsection{Synthesis}

AuNRs are commonly synthesized through seed or seedless mediation [45, 51, 52]. Seed mediation is a three-step process of taking a face-cantered cubic (FCC) structure metal like Au and creating a nanorod [45]. These steps include seed preparation by heavily reducing a gold precursor, preparation of the growth solution with a weak reducing agent, and finally the addition of gold seeds in the growth solution [45]. The seeds allow for the nanorod growth outwards in one direction [45]. Seed mediation dates back to 2001 when Jana et al. [53] pioneered the method of seed-mediated nanorod growth. Seed-mediation is limited by the number of spherical particle by-products and has a low yield [45]. Seedless mediation uses sodium borohydride as a seed substitute and is effective at creating smaller AuNRs [52]. The use of sodium borohydride as opposed to a seed allows for simultaneous seed formation and AuNR growth but follows a similar method as seed-mediated synthesis [52]. Overall, the formation of AuNRs has a low yield and is a difficult process due to the small nucleation window before isotropic growth occurs [45]. Research into the use of microwaves to reduce synthesis times has shown to decrease the growth period time while also eliminating chemicals that would otherwise be required to stop rod elongation [54]. Williams et al. [54] also noted a reduction in nanorod impurities while using microwave production.

\subsection{Toxicity}

A study by Moros et al. [17] sought to find the toxicity of their previously synthesized $51 \times 7 \mathrm{~nm}$ AuNRs. To test the toxicity in vitro, glucose was attached to increase the uptake by cells [17]. Melanoma cells (B16-F10) were incubated with AuNRs for a day and then an MTT assay was used to measure metabolic activity and overall cell viability [17, 55]. This is ultimately a colorimetric assay that depends on mitochondrial oxidation of the cells in question [55]. Fluorescence microscopy was used to ensure that uptake of AuNRs by the cells occurred [17]. The results of this study indicated that the AuNR cell uptake was $1.62 \mathrm{pg} \mathrm{Au/cell} \mathrm{and} \mathrm{no} \mathrm{toxic} \mathrm{effects} \mathrm{on} \mathrm{the} \mathrm{cells} \mathrm{were} \mathrm{observed} \mathrm{[17].}$

A high dose toxicity test was also performed using hydra, a small freshwater hydrozoa used in testing [17]. Hydra polyps were placed in a solution of AuNPs $(1 \mathrm{mg} / \mathrm{mL})$ and incubated for $24 \mathrm{~h}$ with and without PEC [17]. The AuNRs without PEG and with cetyl trimethylammonium bromide (CTAB) caused total animal destruction whereas the PEGlycated AuNRs showed no damage to the hydra [17]. This suggests that the PEGlycated AuNRs therefore are safe for human use since hydra are effective at modelling human reactions [17]. CTAB is difficult to be removed from the nanorod causing the non-toxic form of AuNRs to be hard to safely manufacture. CTAB is necessary to direct rod growth but is also challenging to detect in solution due to its structure $[56,57]$.

A study by Ali et al. [58] found similar results for AuNR toxicity, where they injected a single dose of $25 \mathrm{~nm}$ AuNRs into mice and then assessed the histopathology of vital organs at increasing time increments for up to 15 months. No negative side effects were found in the liver, spleen, lungs or kidneys and the mice also showed no visual signs of toxicity [58]. Using TEM, it was verified that there was an uptake of AuNRs and some remained after 15 months without structural changes [58]. The highest levels of uptake were in the spleen with $78 \mathrm{ng}$ of Au per mg of dry tissue after 2 days and decreased to $35 \mathrm{ng}$ of Au per $\mathrm{mg}$ of dry tissue after 15 months [58]. The decrease in concentration is seen throughout the body due to some AuNPs being removed in excrement [58]. 


\subsection{Effect of Aspect Ratio on Heating Effectiveness}

The percentage of extinction that a plasmonic NP converts to heat increases as the particle size decreases [59]. Decreasing particle size also decreases the value of extinction itself [59]. Since these factors trend oppositely with size, this means there is an optimal size for maximizing heat generation within the AuNP size range [59]. Mackey et al. [52] compared how changing the aspect ratio of AuNRs would affect their heating capabilities in PTT. The group created three sizes of AuNRs $(38 \times 11,28 \times 8$, and $17 \times 5 \mathrm{~nm})$ to use for comparison [52]. The larger AuNRs were created using seed-mediated growth, creating AuNRs with an approximate width and length of $11 \mathrm{~nm}$ and $38 \mathrm{~nm}$, respectively [52]. The LSPR of these NRs was approximately $740 \mathrm{~nm}$ [52]. The smaller AuNRs were produced with a seedless chemistry method and a sodium borohydride seed substitute [52]. This resulted in AuNRs with dimensions of 28x8 $\mathrm{nm}$ and $17 \times 5 \mathrm{~nm}$ and LSPRs of $770 \mathrm{~nm}$ and $755 \mathrm{~nm}$, respectively [52]. These parameters are summarized in Table 3. These three sizes of AuNRs were then tested for their photothermal heating properties in solution by diluting them in $\mathrm{H}_{2} \mathrm{O}$ until they possessed the same optical density and then exposing them to a NIR laser with a wavelength of $808 \mathrm{~nm}$ at $5.8 \mathrm{~W} / \mathrm{cm}^{2}$ [52].

A photothermal heat conversion factor was determined for each of the three sizes of AuNRs by multiplying the change in temperature per AuNR by a factor of $10^{11}$ to increase the ease of comparison [52]. The findings from this study are shown in Figure 2 [52]. It can be seen in Figure 2 that the $28 \mathrm{~nm}$ AuNR was the optimal size for use in PTT, as it had a greatest heat conversion factor for treatment times of 1 and 2 minutes with a maximum temperature change of $2.5 \times 10^{-11}{ }^{\circ} \mathrm{C} /$ particle [52]. As the $28 \mathrm{~nm}$ AuNRs had the best aspect ratio for optimal heating, this size produces the best balance between the percentage of extinction that is converted to heat and the size-extinction dependency [52]. The $17 \times 5 \mathrm{~nm}$ AuNR showed poor results comparatively [52].

Table 3: Overview of AuNR's Parameters [52]

\begin{tabular}{ccc}
\hline Size $(\mathrm{nm})$ & Seeded & LSPR $(\mathrm{nm})$ \\
\hline $38 \times 11$ & Yes & 740 \\
$28 \times 8$ & No & 770 \\
$17 \times 5$ & No & 755 \\
\hline
\end{tabular}

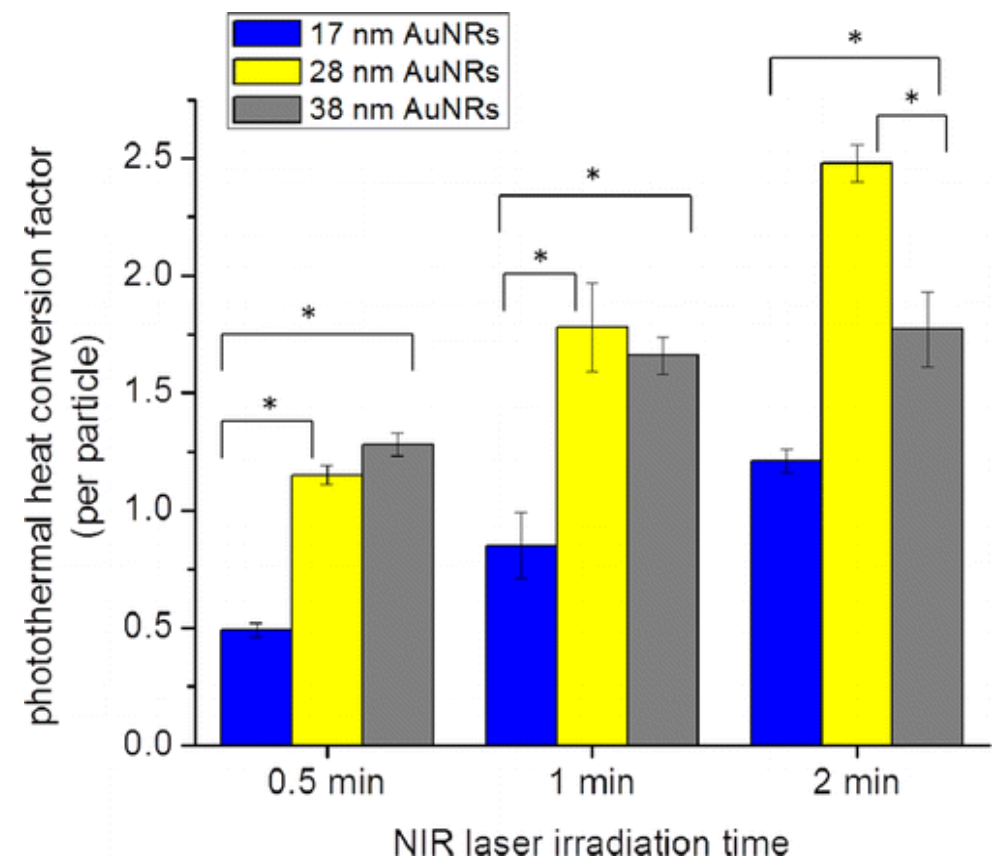

Figure 2: Comparison of Photothermal Heat Conversion Factors Based on Irradiation Times with a NIR Laser and the Size of AuNRs [52]. 


\subsection{Selective Photothermal-Induced Cell Death}

To determine the effectiveness of PTT with AuNRs, Moros and colleagues [17] used melanoma cells (B16-F10) that were incubated with AuNRs for a day and then irradiated with a laser at intensities of $3,4.5$, and $30 \mathrm{~W} / \mathrm{cm}^{2}$ for 3 min [17]. The dish temperature was kept below $43^{\circ} \mathrm{C}$ to ensure cell death was only caused by hotspots generated by the AuNRs [17]. After $5 \mathrm{hr}$ of recovery time, the cell's conditions were monitored [17]. It was found that the AuNRs killed approximately $70 \%$ of the targeted tumour cells at 4.5 and $30 \mathrm{~W} / \mathrm{cm}^{2}$, but no cell deaths at $3 \mathrm{~W} / \mathrm{cm}^{2}$ [17]. At $1 \mathrm{hr}$ post irradiation, the cells remained expanded with a blebbing membrane, signifying apoptotic cell death [17]. Similar effects were also found by Soni et al. [60], where it was shown that the surrounding tissue was spared during the PTT using AuNRs. This study showed that increasing the rod diameter could lead to an increase in photon scattering, which could result in damage to surrounding tissue [60]. A rod diameter increase from 5 to $15 \mathrm{~nm}$ increased the scattering coefficient by a factor of 76 with an increase in absorption efficiency by a factor of only 1.7 [60]. Experiments performed by Zhang et al. [61] found a decline in absorbance peaks after a significant period of laser exposure using an $808 \mathrm{~nm}$ laser at $0.8 \mathrm{~W} / \mathrm{cm}^{2}$. The group also found that the AuNRs exhibited the "melting effect" and underwent morphological changes to form approximately spherical AuNPs [61]. This change resulted in an overall change in absorption and indicated instability in the AuNRs [61].

\section{GOLD NANOSHELLS}

AuNShs consist of a core material that lacks electrical conductivity and a gold shell [62, 63]. There are many variations in the cores of nanoshells, such as gold-sulfide, polystyrene latex sphere, and silica [55]. These types of nanoshells appear to be promising for cancer treatment, as their optical properties have a changeable plasmon resonance in the NIR region [55]. Specific types of AuNSh have size limitations and can potentially form by-products during the fabrication process that can negatively interfere with the hyperthermia treatment $[64,55]$. A key disadvantage for the use of polystyrene latex cores is that their resonances cannot produce sufficient heat to kill cancer cells in tumours [55]. Studies that used an $\mathrm{Au}_{2} \mathrm{~S}$ core with a gold shell found this to have a suitable absorbance peak of $520-900 \mathrm{~nm}$ [63]. An additional limitation in the synthesis of $\mathrm{Au}_{2} \mathrm{~S}$ nanoshells is that the core and shell cannot be controlled independently [63]. They are dealt with as one structure, not as a separate shell and core, and this can produce harmful by-products that cannot be removed [63].

Though there are a plethora of options, the most effective AuNSh has been found to be the silica-gold nanoshell (AuSiNSh), which was developed around 25 years ago [55]. AuSiNShs show great promise with their structural integrity and adjustable resonance $[26,55]$. This tunable plasmon resonance is significant in hybrid nanoshells of different materials, as they can be tailored to absorb or scatter light in the visible to NIR region $[55,10]$. The potential biomedical applications of AuSiNShs include cancer hyperthermia treatment [10].

\subsection{Synthesis}

A common method of synthesis is the Stober method, which consists of the silica core being grown to create particles with a 60 to $400 \mathrm{~nm}$ diameter $[26,55,63]$. There are drawbacks in this range, as the higher values are not considered to be NPs and could potentially cause issues during treatment and may not be a suitable size for PTT [13]. In this method, an ethanol solution is used to reduce tetraethyl orthosilicate, allowing for the spherical silica colloid particles to begin to grow and develop in size [63]. Reactions occur between the aminopropyltriethoxysilane and the silica surface to make it functional, which allows Au colloid to be adsorbed and create the outer shell [63]. This Au colloid layer will then be reduced by a $\mathrm{HAuCl}_{4}$ solution, which allows the Au colloid layer to grow to the desired thickness [63]. This NP evidently has a broad diameter range and researchers should be aware and stay within the optimal range for cancer treatment [63]. Another factor to consider is that the Stober Method is quite complicated and can produce unwanted toxic by-products [63].

In 2020, Riedel et al. [64] investigated the pulsed laser ablation in liquid method (PLAL) for the synthesis of AuSiNSh. This method has not yet been extensively researched for creating AuSiNSh for PTT; this is not its primary application [64]. This study appeared to have found a more straightforward process to synthesize AuSiNShs [64]. In this process, a laser was focused onto a rotating gold target submerged in a $\mathrm{NaSiO}_{2}$ and distilled water solution; the laser was focused for $15 \mathrm{~min}$ [64]. The ablation process resulted in AuSiNShs that had a diameter of $9 \mathrm{~nm}$ and a shell thickness of $2 \mathrm{~nm}[64]$.

\subsection{Toxicity}

A study performed by Sang-Eun et al. [55] investigated how AuSiNSh with a clustered shell impacts the effectiveness of hyperthermia treatment. This method involved two different types of AuSiNShs, one being entirely covered with gold clusters (f-SGNS) and the other being partially covered with disconnected gold-clusters (p-SGNS) [55]. These nanoshells were both conjugated with Erbitux (ERB-SCNSh), an antibody target that binds to tumour-specific antigens, which is useful for tumour cell targeting [55].

The cytotoxicity of p-ERB-SCNS and f-ERB-SCNS was measured using a MTT assay prior to a laser treatment to measure photothermal performance [55]. The human epidermoid carcinoma cells were treated with p-ERB-SCNS and f-ERB-SCNS and incubated overnight [55]. Cellular viabilities were analysed for both untreated and treated cancer cells; the treatment consisted ofp-ERB-SCNS and f-ERB-SCNS [55]. The ratio of the intensity of the purple 
formazan present in the cancer cells after incubation was measured [55]. The results demonstrated that p-ERB-SCNS and f-ERB-SGNS have a low cytotoxicity, as there was an $80 \%$ cell viability before irradiation [55].

A study conducted by Majidi et al. [65] used conjugated silica-gold nanoshells with folic acid (FA-SiO $\left.{ }_{2} @ A u\right)$ as a tumour targeting agent, similarly to the ERB in the past study. In this experiment, a sample of melanoma cells and healthy cells were treated with $100 \mu \mathrm{g} / \mathrm{ml}$ concentration of FA-SiO $\mathrm{S}_{2} @ \mathrm{Au}$ and $\mathrm{SiO}_{2} @ \mathrm{Au}$ [65]. After the incubation period, both $\mathrm{FA}-\mathrm{SiO}_{2} @ \mathrm{Au}$ and $\mathrm{SiO}_{2} @ A u$ were found to be non-toxic to healthy cells, but toxic to cancer cells [65]. The cancer cells showed a significant drop in cell viability after the incubation period [65]. Another study by Riedel et al. [64] performed an in vivo test, where mice were intravenously injected with unconjugated AuSiNShs and the concentrations in the organs after $24 \mathrm{hr}$ were measured. The results are displayed in Figure 3 [64]. These AuSiNShs were synthesized using the PLAL method [64]. This study found a positive observation that there was no accumulation of the NP in the brain due to the blood-brain barrier [64]. It was also found that no damage occurred in the heart, liver, spleen, lungs, and kidneys [64]. The concentration of NPs in the organs decreased with time, and the particles degraded quickly in the body [64]. This further implies that the results from Riedel and coworkers' [64] study found that the PLAL method of synthesizing AuSiNShs was a much simpler process that demonstrated a lower toxicity in comparison.

\subsection{Selective Photothermal-Induced Cell Death}

Sang et al. [55] also investigated the photothermal performance of AuSiNShs by treating epidermoid carcinoma cells with f-ERB-SGNS and p-ERB-SGNS. After treatment, they were incubated at $37^{\circ} \mathrm{C}$ in Dulbecco's Modified Eagle's Medium (DMEM) that contained 10\% fetal bovine serum and 1\% antibiotics. Cells were then exposed to a NIR laser at $820 \mathrm{~nm}$ at a power of $35 \mathrm{~W} / \mathrm{cm}^{2}$ for approximately 5 min [55].

This experiment found that more thermal energy was produced within the tumour that was treated with $\mathrm{f}$-ERBSGNS than p-ERB-SGNS [55]. Both nanoshells were found to have an absorption peak around 700-820 nm, which is promising as it falls within the NIR region [55]. This study also found that there was a reduction in plasmon bands due to the accumulation of gold particles on the shell during synthesis [55]. Their main finding was that AuSiNShs with a thick shell produce the strongest absorption band, but also the lowest solution temperature increase in comparison to the AuSiNShs with thinner shells [55]. Overall, this indicates there was a lower hyperthermia effect when using NPs with thicker shells due to dissipation within the thicker shell [55]. The cell death was measured after irradiation and it was found that the control group had a 100\% cell viability with no cell deaths, whereas the f-ERBSGNS and p-ERB-SGNS treatment groups had $20.6 \%$ and $45.3 \%$ cell viability, respectively [55].

Majidi et al. [65] used a similar process to the one used in the previous study, but the power intensity varied. An in-vitro test was conducted to investigate FA-SiO ${ }_{2} @ A$ Au photothermal performance on melanoma cancer cells [65]. As mentioned, cancer cells were treated with FA-SiO $2 @ A u$ and $\mathrm{SiO}_{2} @ A u$ prior to irradiation [65]. FA-SiO $\mathrm{S}_{2} @ \mathrm{Au}$ and $\mathrm{SiO}_{2} @ \mathrm{Au}$ were absorbed in 10\% DMEM and incubated at $37^{\circ} \mathrm{C}$ for $24 \mathrm{hr}$ [65]. These cells were exposed to laser

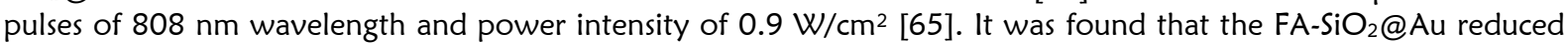

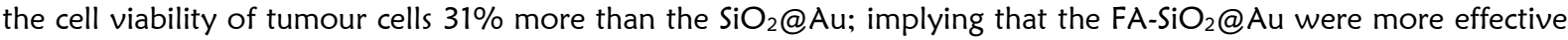
[65]. The study concluded that there was an overall 87\% tumour cell death due to the use of FA-SiO ${ }_{2} @ A u$ [65].

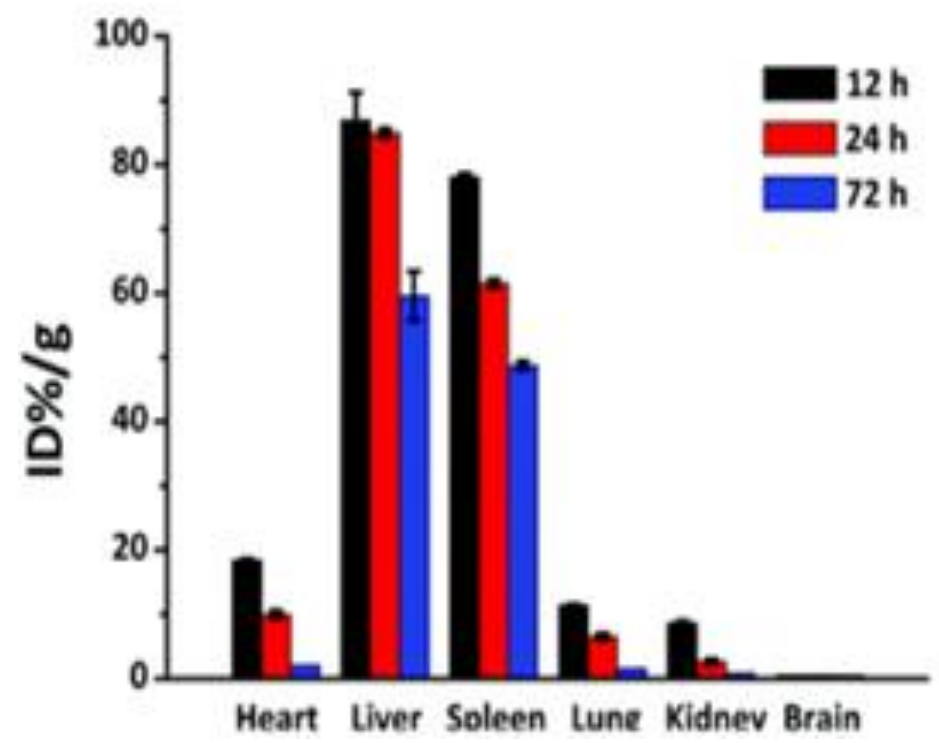

Figure 3: The concentration of AuSiNShs in major organs after 12, 24, and $72 \mathrm{hr}$ periods post-injection [64]. 


\section{DISCUSSIONS}

AuNSs appear to be the optimal choice given the parameters of the absorption spectrum, toxicity, selective cell killing ability, size, synthesis, and additional qualitative advantages and disadvantages. The absorption spectrum for all of the NPs considered landed within the NIR region, therefore making them viable for use in PTT $[10,29,38,50,55]$. All four shapes have also been found to have low toxicity, indicating that they would cause minimal harm to healthy tissue and could be viable candidates for cancer hyperthermia treatment $[38,55,63,66]$. However, due to the wellknown safety of AuNSs and their ability to be used in PTT without surface coatings [35], these appear to have the lowest risk of causing toxic effects if used in vivo in humans for hyperthermia cancer treatment.

Each AuNP produced high percentages of tumour cell death with few control cells killed [17, 29, 35, 65]. When comparing these results, it is notable that the following differences between experiments might have affected results: cell type, AuNPs concentration, power densities, and irradiation duration. Despite these differences, certain conclusions can be drawn. The best selective cell killing was found with AuNSs, with 100\% tumour cell death [35]. The study by Huang et al. [43] found that when using a NIR laser, 20 times less power was required to kill cells treated with aggregates of antibody-conjugated AuNSs relative to control cells. This is comparable to 2 times less laser power when $514 \mathrm{~nm}$ light was used by El-Sayed et al. [35], suggesting that selective cell killing using AuNSs would be further improved using Huang and coworkers' [43] method. These results indicate that AuNSs produced the highest percentage of selective tumour cell killing while inflicting minimal damage in healthy tissue [35].

Since AuNPs need to enter the tissue before PTT irradiation, it is advantageous for them to be adjustable and smaller in size so they can selectively accumulate in tumours with varying sizes of fenestrations [10, 17]. AuNSs are functional with sizes down to a diameter of $3 \mathrm{~nm}$, the smallest of the 3 other AuNPs compared as shown in table 5 [40]. This small size is important to be able to accumulate in immature tumours with smaller fenestrations [10].

The synthesis of medical technology should be rapid and efficient to optimize overall production and minimize costs [67]. AuNSs can be synthesized through a rapid reduction of $\mathrm{HAuCl}_{4}$, which is simple in comparison to the synthesis of other AuNPs. Their ability to be produced using a rapid, highly efficient microwave-aided method is a promising avenue for large, commercial scale production, which can reduce costs [39, 67, 68, 69]. Furthermore, particle size can also be adjusted through controlling reaction times and temperatures [39, 40]. AuNSs' synthesis is efficient [10] and can be easily modified to create AuNS ranging from 3-100 nm [40].

AuNSs have the ability to be easily conjugated to various antibodies, improving the ability to accumulate in tumour tissue selectively [35]. Lastly, the use of AuNS provides a unique opportunity to simultaneously image the photothermal-induced damage during treatment due to the production of microbubbles [10, 44]. Overall, these advantages of AuNSs over other AuNPs make them ideal for PTT to potentially improve the prognosis and quality of cancer treatment for many patients in the future.

Table 4: Summary of Targeted Cancer Cell Killing Studies by AuNP type. Sources: $[17,29,35,65]$

\begin{tabular}{|c|c|c|c|c|}
\hline NP Type & $\begin{array}{l}\text { Cells/ } \\
\text { animal }\end{array}$ & $\begin{array}{c}\text { Laser Power Density } \\
\qquad\left(\mathrm{W} / \mathrm{cm}^{2}\right)\end{array}$ & $\begin{array}{l}\text { Irradiation Length } \\
\text { (min) }\end{array}$ & \% Tumour Cell Death \\
\hline AuNC[29] & Mice & 0.7 & 10 & 70 \\
\hline AuNS[35] & Cells & $\begin{array}{l}25 \\
19\end{array}$ & $\begin{array}{l}4 \\
4\end{array}$ & $\begin{array}{l}100 \text { (HSC) } \\
100 \text { (HOC) }\end{array}$ \\
\hline AuNR[17] & Cells & $\begin{array}{l}4.5 \\
30\end{array}$ & $\begin{array}{l}3 \\
3\end{array}$ & $\begin{array}{l}70 \\
70\end{array}$ \\
\hline AuSiNSh ${ }^{[65]}$ & Cells & 0.9 & 5 & 87 \\
\hline
\end{tabular}

Table 5: Summary of typical particle sizes. Sources: $[29,40,52,63]$. $* 9 \mathrm{~nm}$ diameter AuSiNShs have recently been formed using PLAL technology [64]

\begin{tabular}{|c|c|}
\hline NP Type & Dimension (nm) \\
\hline AuNC[29] & $\begin{array}{l}\text { Edge length: } 47 \\
\text { Diameter: } 99\end{array}$ \\
\hline AuNS[40] & Diameter: 3-100 \\
\hline AuNR[52] & $\begin{array}{l}\text { Diameter: 5-11 } \\
\text { Length: } 17-51\end{array}$ \\
\hline AuSiNSh ${ }^{[63]}$ & Diameter: $9 *$ or $60-400$ \\
\hline
\end{tabular}




\section{CONCLUSIONS AND FURURE RECOMMENDATIONS}

1. Nanoparticle-enhanced photothermal therapy presents a promising opportunity to advance cancer treatment beyond current methods that frequently cause non-specific damage to healthy tissues and undesirable side effects. Ideally, the particles would cause no toxic effects in vivo, be fast and easy to synthesize without toxic byproducts, be able to selectively kill all tumour cells during PTT and have a maximum surface plasmon absorption in the NIR region.

2. The use of gold is optimal due to its high biocompatibility, corrosion-resistance, low toxicity, and strong absorption of radiation in the NIR and visible light regions.

3. AuNSs appear to be the most effective AuNP for the treatment of cancer using nanoparticle-enhanced PTT. These have been shown to outperform AuNRs, AuNCs, and AuSiNShs in the categories of toxicity, selective cell killing, and synthesis. In addition, they can be a sufficiently small size to accumulate in tumour tissue and their absorption peak can be shifted to the NIR region.

4. AuSiNShs are another promising method for PTT when they are synthesized through the PLAL method, as this is more time-efficient than the conventional Stober method $[63,64]$. This reduces the AuSiNShs' diameter range to fall within the range of a NP [13]. However, this method has not been extensively researched and further work in this area is required to fully validate this method [64].

5. With 225,800 Canadians expected to be diagnosed with cancer in 2020, AuNSs should be further researched for use in AuNP-enhanced PTT. [70]. Further testing must be performed to ensure the safety of AuNPs in vivo in humans. Additionally, while studies have shown forms of AuNPs to be acutely non-toxic in rodent models, the long-term effects of these particles in vivo must be rigorously tested to ensure their safety moving forward from preclinical to clinical studies.

6. AuNPs provide a promising opportunity to provide highly targeted and selective cancer treatments, unique from many currently in use. Their unique properties and effective use in PTT have been shown preclinically, demonstrating their potential to help improve the outcome and quality of life for future cancer patients.

\section{REFERENCES}

1. Canadian Cancer Statistics Advisory Committee. (2019). Canadian Cancer Statistics. Toronto, ON: Canadian Cancer

https://www.cancer.ca/ /media/cancer.ca/CW/cancer\%20information/cancer\%20101/Canadian\%20cancer\% 20statistics/Canadian-Cancer-Statistics-2019-EN.pdf?la =en

2. Brenner, D. R., Weir, H. K., Demers, A. A., Ellison, L. F., Louzado, C., Shaw, A., Turner, D., Woods, R., \& Smith, L. Canadian Cancer Statistics Advisory Committee. (2020). Projected estimates of cancer in Canada in 2020. CMAJ: Canadian Medical Association Journal = Journal De l'Association Medicale Canadienne, 192(9), E199E205. doi:10.1503/cmaj.191292

3. Oliveira, C. D., Pataky, R., Bremner, K. E., Rangrej, J., Chan, K. K. W., Cheung, W. Y., Hoch, J. S., Peacock, S., \& Krahn, M. D. (2017). Estimating the cost of cancer care in British Columbia and Ontario: A Canadian interprovincial comparison. Healthcare Policy/Politiques De Santé, 123), 95-108. doi:10.12927/hcpol.2017.2502

4. Sun, T., Zhang, Y. S., Pang, B., Hyun, D. C., Yang, M., \& Xia, Y. (2014). Engineered nanoparticles for drug delivery in cancer therapy. Angewandte Chemie International Edition, 53(46), 12320-12364. doi:10.1002/anie.201403036

5. Kudarha, R. R., \& Sawant, K. K. (2017). Albumin based versatile multifunctional nanocarriers for cancer therapy: Fabrication, surface modification, multimodal therapeutics and imaging approaches. Materials Science \& Engineering C, 81, 607-626. doi:10.1016/j.msec.2017.08.004

6. Stone, J. B., \& DeAngelis, L. M. (2016). Cancer-treatment-induced neurotoxicity--focus on newer treatments. Nature Reviews. Clinical Oncology, 13(2), 92-105. doi:10.1038/nrclinonc.2015.152

7. Trautinger, F., Eder, J., Assaf, C., Bagot, M., Cozzio, A., Dummer, Reinhard., Gniadecki, R., Klemke, C. D., Ortiz-Romero, P. L., Papadavid, E., Pimpinelli, N., Quaglino, P., Ranki, A., Scarisbrick, J., Stadler, R., Väkevä, L., Vermeer, M. H., Whittaker, S., Willemze, R., Knobler, R. (2017). European organisation for research and treatment of cancer consensus recommendations for the treatment of mycosis fungoides/Sézary syndrome update 2017. European Journal of Cancer, 77, 57-74. doi:10.1016/j.ejca.2017.02.027

8. Fletcher, C., Wilson, C., Hutchinson, A. D., \& Grunfeld, E. A. (2018). The relationship between anticipated response and subsequent experience of cancer treatment-related side effects: A meta-analysis comparing effects before and after treatment exposure. Cancer Treatment Reviews, 68, 86-93. doi:10.1016/j.ctrv.2018.06.009

9. National Cancer Institute. (2019, January 18). Radiation Therapy to Treat Cancer. National Cancer Institute at the National Institutes of Health, U.S. Department of Health and Human Services. https://www.cancer.gov/about-cancer/treatment/types/radiation-therapy

10. Kennedy, L. C., Bickford, L. R., Lewinski, N. A., Coughlin, A. J., Hu, Y., Day, E. S., West, J.L., \& Drezek, R.A. (2011). A new era for cancer treatment: Gold-Nanoparticle-Mediated thermal therapies. Small, 7(2), 169-183. doi:10.1002/smll.201000134 
11. Avedisian, C. T., Cavicchi, R. E., McEuen, P. L., \& Zhou, X. (2009). Nanoparticles for cancer treatment: Role of heat transfer. Annals of the New York Academy of Sciences, 11611), 62-73. doi:10.1111/j.1749. 6632.2009.04090.x

12. Mirzajavadkhan, A., Rafieian, S., \& Hasan, M. H. (2020). Toxicity of Metal Implants and Their Interactions with Stem Cells: A Review. International Journal of Engineering Materials and Manufacture, 5(1), 2-11. https://doi.org/10.26776/ijemm.05.01.2020.02

13. Aghebati-Maleki, A., Dolati, S., Ahmadi, M., Baghbanzhadeh, A., Asadi, M., Fotouhi, A., Yousefi, M., \& Aghebati-Maleki, L. (2020). Nanoparticles and cancer therapy: Perspectives for application of nanoparticles in the treatment of cancers. Journal of Cellular Physiology, 235(3), 1962-1972. doi:10.1002/jcp.29126

14. Gerber, A., Bundschuh, M., Klingelhofer, D., \& Groneberg, D. A. (2013). Gold nanoparticles: Recent aspects for human toxicology. Journal of Occupational Medicine and Toxicology (London, England), 8(1), 32-32. doi:10.1186/1745-6673-8-32

15. Huang, X., Jain, P. K., El-Sayed, I. H., \& El-Sayed, M. A. (2006). Determination of the minimum temperature required for selective photothermal destruction of cancer cells with the use of immunotargeted gold nanoparticles. Photochemistry and Photobiology, 82(2), 412-417. doi:10.1562/2005-12-14-RA-754

16. Yang, W., Liang, H., Ma, S., Wang, D., \& Huang, J. (2019). Gold nanoparticle based photothermal therapy: Development and application for effective cancer treatment. Sustainable Materials and Technologies, 22, e00109. doi:10.1016/j.susmat.2019.e00109

17. Moros, M., Lewinska, A., Merola, F., Ferraro, P., Wnuk, M., Tino, A., \& Tortiglione, C. (2020). Gold nanorods and nanoprisms mediate different photothermal cell death mechanisms in vitro and in vivo. ACS Applied Materials \& Interfaces. doi:10.1021/acsami.0c02022

18. FarrokhTakin, E., Ciofani, G., Puleo, G. L., de Vito, G., Filippeschi, C., Mazzolai, B., Vincenzo, P., Mattoli, V. (2013). Barium titanate core--gold shell nanoparticles for hyperthermia treatments. International Journal of Nanomedicine, 8(1), 2319-2331. doi:10.2147/IJN.S45654

19. Cherukuri, P., Glazer, E. S., \& Curley, S. A. (2010). Targeted hyperthermia using metal nanoparticles. Advanced Drug Delivery Reviews, 62(3), 339-345. doi:10.1016/j.addr.2009.11.006

20. Jha, S., Sharma, P., \& Malviya, R. (2016). Hyperthermia: Role and Risk Factor for Cancer Treatment. Achievements in the Life Sciences, 10(2), 161-167.

21. Dykman, L., \& Khlebtsov, N. (2012). Gold nanoparticles in biomedical applications: Recent advances and perspectives. Chemical Society Reviews, 41(6), 2256-2282. doi:10.1039/C1CS15166E

22. Petryayeva, E., \& Krull, U. J. (2011). Localized surface plasmon resonance: Nanostructures, bioassays and biosensing-A review. Analytica Chimica Acta, 706(1), 8-24. doi:10.1016/j.aca.2011.08.020

23. Lu, Y., \& Mahato, R. I. (2009). Pharmaceutical perspectives of cancer therapeutics. Springer US.

24. Dreaden, E., Alkilany, A., Huang, X., Murphy, C., \& El-sayed, M. (2012). The golden age: Gold nanoparticles for biomedicine. Chemical Society Reviews, 41(7), 2740-2779.

25. Huang, X., \& El-Sayed, M. A. (2010). Gold nanoparticles: Optical properties and implementations in cancer diagnosis and photothermal therapy. Journal of Advanced Research, 1(1), 13-28. https://doi.org/10.1016/j.jare.2010.02.002

26. Everts, M. (2007). Thermal scalpel to target cancer. Expert Review of Medical Devices, 4(2), 131-136. doi:10.1586/17434440.4.2.131

27. Huang, Y., Cambre, M., \& Lee, H. (2017). The toxicity of nanoparticles depends on multiple molecular and physicochemical mechanisms. International Journal of Molecular Sciences, 18(12), 2702. doi:10.3390/ijms18122702

28. Su, Y., Wei, X., Peng, F., Zhong, Y., Lu, Y., Su, S., Xu, T., Lee, S., He, Y. (2012). Gold nanoparticles-decorated silicon nanowires as highly efficient near-infrared hyperthermia agents for cancer cells destruction. Nano Letters, 12(4), 1845-1850. doi:10.1021/nl204203t

29. Chen, J., Glaus, C., Laforest, R., Zhang, Q., Yang, M., Gidding, M., Welch, M. J., \& Xia, Y. (2010). Gold nanocages as photothermal transducers for cancer treatment. Small, 6(7), 811-817. doi:10.1002/smll.200902216

30. Rengan, A. K., Kundu, G., Banerjee, R., \& Srivastava, R. (2014). Gold nanocages as effective photothermal transducers in killing highly tumorigenic cancer cells. Particle \& Particle Systems Characterization, 31(3), 398405. doi:10.1002/ppsc.201300173

31. Zeng, J., Goldfeld, D., \& Xia, Y. (2013). A Plasmon-Assisted optofluidic (PAOF) system for measuring the photothermal conversion efficiencies of gold nanostructures and controlling an electrical switch. Angewandte Chemie International Edition, 52(15), 4169-4173. doi:10.1002/anie.201210359

32. Feng, Y., Cheng, Y., Chang, Y., Jian, H., Zheng, R., Wu, X., Xu, K., Wang, L., Ma, X., Li, X., Zhang, H. (2019). Time-staggered delivery of erlotinib and doxorubicin by gold nanocages with two smart polymers for reprogrammable release and synergistic with photothermal therapy. Biomaterials, 217, 119327. doi:10.1016/j.biomaterials.2019.119327

33. Jenkins, S. V., Nedosekin, D. A., Shaulis, B. J., Wang, T., Jamshidi-Parsian, A., Pollock, E. D., Chen, J., Dings, R. R. M., \& Griffin, R. J. (2019). Enhanced photothermal treatment efficacy and normal tissue protection via vascular targeted gold nanocages. Nanotheranostics, 3(2), 145-155. doi:10.7150/ntno.32395 
34. Panikkanvalappil, S. R., Hooshmand, N., \& El-Sayed, M. A. (2017). Intracellular Assembly of Nuclear-Targeted Gold Nanosphere Enables Selective Plasmonic Photothermal Therapy of Cancer by Shifting Their Absorption Wavelength toward Near-Infrared Region. Bioconjugate Chemistry, 28(9), 2452-2460. https://doi.org/10.1021/acs.bioconjchem.7b00427

35. El-Sayed, I. H., Huang, X., \& El-Sayed, M. A. (2006). Selective laser photo-thermal therapy of epithelial carcinoma using anti-EGFR antibody conjugated gold nanoparticles. Cancer Letters, 239(1), 129-135. doi:10.1016/j.canlet.2005.07.035

36. El-Sayed, I. H., Singer, M. I., \& Civantos, F. (2005). Sentinel lymph node biopsy in head and neck cancer. Otolaryngologic Clinics of North America, 145-160. https://doi.org/https://doi.org/10.1016/j.otc.2004.09.004

37. Sherman, A. I., Ter-Pogossian, M., \& With The Technical Assistance Of Edward C Tocus. (1953). Lymph-node concentration of radioactive colloidal gold following interstitial injection. Cancer, 6(6), 1238-1240. https://doi.org/10.1002/1097-0142(195311)6:6<1238::AID-CNCR2820060618>3.0.CO;2-6

38. Pitsillides, C. M., Joe, E. K., Wei, X., Anderson, R. R., \& Lin, C. P. (2003). Selective Cell Targeting with LightAbsorbing Microparticles and Nanoparticles. Biophysical Journal, 84(6), 4023-4032. doi:10.1016/500063495(03)75128-5

39. Liu, F., Ker, C., Chang, Y., Ko, F., Chu, T., \& Dai, B. (2003). Microwave heating for the preparation of nanometer gold particles. Japanese Journal of Applied Physics, 42(Part 1, No. 6B), 4152-4158. doi:10.1143/JJAP.42.4152

40. Chen, Y., Hung, Y., Liau, I., \& Huang, G. S. (2009). Assessment of the in vivo toxicity of gold nanoparticles. Nanoscale Research Letters, 4(8), 858-864. doi:10.1007/s11671-009-9334-6

41. Huang, X., Jain, P., El-Sayed, I., \& El-Sayed, M. (2008). Plasmonic photothermal therapy (PPTT) using gold nanoparticles. Lasers in Medical Science, 23(3), 217-228.

42. Cheng, X., Sun, R., Yin, L., Chai, Z., Shi, H., \& Gao, M. (2017). Light-Triggered Assembly of Gold Nanoparticles for Photothermal Therapy and Photoacoustic Imaging of Tumors In Vivo. Advanced Materials, 29(6), 1604894. https://doi.org/10.1002/adma.201604894

43. Huang, X., Qian, W., El-Sayed, I. H., \& El-Sayed, M. A. (2007). The potential use of the enhanced nonlinear properties of gold nanospheres in photothermal cancer therapy. Lasers in Surgery and Medicine, 39(9), 747753. doi:10.1002/lsm.20577

44. Lapotko, D., Lukianova, E., Potapnev, M., Aleinikova, O., \& Oraevsky, A. (2006). Method of laser activated nano-thermolysis for elimination of tumour cells. Cancer Letters, 239(1), 36-45. doi:10.1016/j.canlet.2005.07.031

45. Chhatre, A., Thaokar, R., \& Mehra, A. (2018). Formation of gold nanorods by seeded growth: Mechanisms and modeling. Crystal Growth \& Design, 18(6), 3269-3282. doi:10.1021/acs.cgd.7b01387

46. Vigderman, L., Khanal, B. P., \& Zubarev, E. R. (2012). Functional gold nanorods: Synthesis, Self-Assembly, and sensing applications. Advanced Materials, 24(36), 4811-4841. doi:10.1002/adma.201201690

47. Kannadorai, R. K., Chiew, G. G. Y., Luo, K. Q., \& Liu, Q. (2014;2015;). Dual functions of gold nanorods as photothermal agent and autofluorescence enhancer to track cell death during plasmonic photothermal therapy. Ireland: Elsevier B.V. doi:10.1016/j.canlet.2014.11.022

48. Brioude, A., Jiang, X. C., \& Pileni, M. P. (2005). Optical properties of gold nanorods: DDA simulations supported by experiments. The Journal of Physical Chemistry B, 109(27), 13138-13142. doi:10.1021/jp0507288

49. Zhao, T., Shen, X., Li, L., Guan, Z., Gao, N., Yuan, P.,Yao, S. Q., Xu, Q., Xu, G. Q. (2012). Gold nanorods as dual photo-sensitizing and imaging agents for two-photon photodynamic therapy. Nanoscale, 4(24), 7712. doi:10.1039/c2nr32196c

50. Nikoobakht, B., \& El-Sayed, M. A. (2003). Preparation and growth mechanism of gold nanorods (NRs) using seed-mediated growth method. Chemistry of Materials, 15(10), 1957-1962. doi:10.1021/cm0207321

51. Scarabelli, L., Sánchez-Iglesias, A., Pérez-Juste, J., \& Liz-Marzán, L. M. (2015). A “Tips and tricks” practical guide to the synthesis of gold nanorods. United States: American Chemical Society. doi:10.1021/acs.jpclett.5b02123

52. Mackey, M. A., Ali, M. R. K., Austin, L. A., Near, R. D., \& El-Sayed, M. A. (2014). The most effective gold nanorod size for plasmonic photothermal therapy: Theory and in vitro experiments. The Journal of Physical Chemistry B, 118(5), 1319-1326. doi:10.1021/jp409298f

53. Jana, N. R., Gearheart, L., \& Murphy, C. J. (2001). Seeding growth for size control of 5-40 nm diameter gold nanoparticles. Langmuir, 17(22), 6782-6786. doi:10.1021/la0104323

54. Williams, M. G., Boyne, D. A., \& Griep, M. H. (2017). Rapid synthesis of high purity gold nanorods via microwave irradiation. Materials Research Express, 4(3), 35040. doi:10.1088/2053-1591/aa66de

55. Sang-Eun Park, Lee, J., Lee, T., Bae, S., Kang, B., Yong-Min, H., Lee, S., \& Haam, S. (2015). Comparative hyperthermia effects of silica-gold nanoshells with different surface coverage of gold clusters on epithelial tumour cells. International Journal of Nanomedicine, 10, 261-271. doi:http://dx.doi.org.ezproxy.lib.ryerson.ca/10.2147/IJN.S88309

56. Smith, D. K., Miller, N. R., \& Korgel, B. A. (2009). lodide in CTAB prevents gold nanorod formation. Langmuir, 25(16), 9518-9524. doi:10.1021/la900757s 
57. He, J., Unser, S., Bruzas, I., Cary, R., Shi, Z., Mehra, R., Aron, K., Sagle, L. (2018). The facile removal of CTAB from the surface of gold nanorods. Colloids and Surfaces, B, Biointerfaces, 163, 140-145. doi:10.1016/j.colsurfb.2017.12.019

58. Ali, M. R. K., Rahman, M. A., Wu, Y., Han, T., Peng, X., Mackey, M. A., Wang, D., Shin, H. J., Chen, Z. G., Xiao, H., Wu, R., Tang, Y., Shin, D. M., El-Sayed, M. A. (2017). Efficacy, long-term toxicity, and mechanistic studies of gold nanorods photothermal therapy of cancer in xenograft mice. Proceedings of the National Academy of Sciences - PNAS, 114(15), E3110-E3118. doi:10.1073/pnas.1619302114

59. Jain, P. K., Lee, K. S., El-Sayed, I. H., \& El-Sayed, M. A. (2006). Calculated absorption and scattering properties of gold nanoparticles of different size, shape, and composition: applications in biological imaging and biomedicine. The Journal of Physical Chemistry B, 110(14), 7238-7248. doi:10.1021/jp057170o

60. Soni, S., Tyagi, H., Taylor, R. A., \& Kumar, A. (2013). Role of optical coefficients and healthy tissue-sparing characteristics in gold nanorod-assisted thermal therapy. International Journal of Hyperthermia, 29(1), 87-97. doi:10.3109/02656736.2012.753162

61. Zhang, P., Wang, J., Huang, H., Yu, B., Qiu, K., Huang, J., Wang, S., Jiang, L., Gasser, G., Ji, L., \& Chao, H. (2015). Unexpected high photothermal conversion efficiency of AuNS upon grafting with two-photon luminescent ruthenium (II) complexes: A way towards cancer therapy? Biomaterials, 63, 102-114. doi:10.1016/j.biomaterials.2015.06.012

62. Nouri, S., Mohammadi, E., Mehravi, B., Majidi, F., Ashtari, K., Neshasteh-Riz, A., \& Einali, S. (2019). NIR triggered glycosylated gold nanoshell as a photothermal agent on melanoma cancer cells. Artificial Cells, Nanomedicine, and Biotechnology, 47(1), 2316-2324. doi:10.1080/21691401.2019.1593187

63. Hirsch, L. R., Gobin, A. M., Lowery, A. R., Tam, F., Drezek, R. A., Halas, N. J., \& West, J. L. (2006). Metal nanoshells. Annals of Biomedical Engineering, 34(1), 15-22. doi:10.1007/s10439-005-9001-8

64. Riedel, R., Mahr, N., Yao, C., Wu, A., Yang, F., \& Hampp, N. (2020). Synthesis of gold-silica core-shell nanoparticles by pulsed laser ablation in liquid and their physico-chemical properties towards photothermal cancer therapy. Nanoscale, 12(5), 3007-3018. doi:10.1039/C9NR07129F

65. Majidi, F. S., Mohammadi, E., Mehravi, B., Nouri, S., Ashtari, K., \& Neshasteh-riz, A. (2019). Investigating the effect of near infrared photo thermal therapy folic acid conjugated gold nano shell on melanoma cancer cell line A375. Artificial Cells, Nanomedicine, and Biotechnology, 47(1), 2161-2170. doi:10.1080/21691401.2019.1593188

66. Rastinehad, A. R., Anastos, H., Wajswol, E., Winoker, J. S., Sfakianos, J. P., Doppalapudi, S. K., Carrick, M.R., Knauer, C. J., Taouli, B., Lewis, S. C., Tewari, A. K., Schwartz, J. A., Canfield, S. E., George, A. K., West, J. L., Halas, N. J. (2019). Gold nanoshell-localized photothermal ablation of prostate tumors in a clinical pilot device study. Proceedings of the National Academy of Sciences of the United States of America, 116(37), 18590-18596. doi:10.1073/pnas.1906929116

67. Nauenberg, E. (2014). Changing healthcare capital-to-labor ratios: Evidence and implications for bending the cost curve in Canada and beyond. International Journal of Health Care Finance and Economics, 14(4), 339. 353. doi:10.1007/s10754-014-9154-9

68. Sreejith Raveendran Anindito Sen Toru Maekawa D. Sakthi Kumar. (2017). Ultra-fast microwave aided synthesis of gold nanocages and structural maneuver studies. Nano Research, 10(3), 1078-1091. doi:10.1007/s12274-0161368-3.

69. World Health Organization (WHO). (2017, February 3). Early cancer diagnosis saves lives, cuts treatment costs. World Health Organization. https://www.who.int/news-room/detail/03-02-2017-early-cancer-diagnosis-saveslives-cuts-treatment-costs

70. Government of Canada. (2020, February 28). Cancer-specific stats 2020. https://www.cancer.ca/ /media/cancer.ca/CW/cancer\%2Oinformation/cancer\%20101/Canadian\%20cancer\% 20statistics\%20supplementary\%20information/2020/2020_cancer-specific-stats.pdf?la=en 